\title{
Changes in water table depth in an oil palm plantation and its surrounding regions in Sumatra, Indonesia
}

\begin{abstract}
This study was carried out to determine changes in depths of water table in an oil palm plantation and its surrounding region. Daily water table depths and daily climatic elements were considered in this study. Eight well point locations were chosen randomly throughout the oil palm plantation. To test relationships among the different variables, correlation coefficients were statistically tested using t-test at 95 and $99 \%$ confidence levels. The results showed that fluctuation depth of the water table at the oil palm area depended on climatic elements. In general, water table depth decreases during dry season and increases during wet season. However, water table depths reduction does not happen permanently. Similarly, water table depths were not changed by oil palm plantation at the oil palm area. Strong correlations were observed between oil palm area and oil palm areas with water table at river side plain. Meanwhile, some other locations were shown to have weak correlation for water table at oil palm and those locations. At oil palm area, water table depth was found to be correlated with some water balance elements such as effective precipitation, soil surface evaporation, run-off and water infiltration rate.
\end{abstract}

Keyword: Water table depth; Watershed; Climate element; Oil palm; Surrounding region 